\title{
Comparison Of FEA Simulations And Experimental Results For As-Built Additively Manufactured Dogbone Specimens
}

Prathamesh Baikerikar

Clemson University

Cameron J Turner ( $\nabla$ cturne9@clemson.edu )

Clemson University https://orcid.org/0000-0001-9546-2328

\section{Research Article}

Keywords: Fused Deposition Modeling (FDM), Finite Element Analysis (FEA), manufacturing technology

Posted Date: March 1st, 2021

DOI: https://doi.org/10.21203/rs.3.rs-203029/v1

License: (c) (i) This work is licensed under a Creative Commons Attribution 4.0 International License.

Read Full License 


\section{Abstract}

Parts built using Fused Deposition Modeling (FDM - an additive manufacturing technology) differ from their design model in terms of their microstructure and material properties. These differences lead to a certain amount of ambiguity regarding the structure, strength and stiffness of the final FDM part. Increasing use of FDM parts as end use products, necessitates accurate simulations and analyses during part design. However, analysis methods such as Finite Element Analysis, are used for analysis of continuum models, and may not accurately represent the non-continuous non-linear FDM parts. Therefore, it is necessary to determine the accuracy and precision of FEA for FDM parts. The goal of this study is to compare FEA simulations of the as-built geometries with the experimental tests of actual FDM parts. Dogbone geometries that include different infill patterns are tested under tensile loading and later simulated using FEA. This study found that FEA results are not always an accurate or reliable means of predicting FDM part behaviors.

\section{Introduction}

In the recent years, engineering and manufacturing sectors have shown an increasing interest in Additive Manufacturing (AM) or 3D printing as a means of manufacturing. From prototypes to functional parts, AM is increasingly being used in the development of new products [1]. According to an industry report by Wohler's Associates' [2] 'Annual Worldwide Progress Report on 3D printing', by 2019, the sale of AM products and services could reach or exceed $\$ 6.5$ billion. With AM, it is possible to develop geometrically complex parts with reduced effort, at the same time AM parts can also be customized for low volume production with economic feasibility. Figure 1 shows use of AM parts in different applications.

AM includes a set of techniques like Fused Deposition Modeling (FDM), Stereo lithography (SLA), Selective Laser Sintering (SLS) and many others to build an object layer-by-layer. This study deals with models developed using FDM. FDM is based on the principal of material extrusion. The process begins in the software stage, where a CAD model of the object is created and saved in an STL file format. Next, a slicing software mathematically slices the CAD model into a number of layers and stores the information in a G-code format for the printer. The extruder of the 3D printer follows this $\mathrm{G}$-code and builds the model from bottom-up by depositing material along geometry of the part on the printer bed. It does this by heating the plastic filament to a semi-molten state and feeding it through the extruder nozzle. Figure 2 diagrams the FDM process. This kind of additive technique enables one to build complex geometries with relative ease, while eliminating the need for assembling complex parts from simple components. The FDM software, defines a solid continuous model with an infill pattern with a sufficiently thick perimeter and a porous infill to save weight. With more research, these infill patterns can be used for function specific purposes as well.

The final part heavily depends on the printing parameters used for creating the part. A higher layer resolution (reduced layer height), produces a finer part finish. Similarly, finer filament widths are better able to represent complex and fine patterns. Since the parts are built filament by filament and layer by 
layer, the microstructure is not as its CAD design, due to the development of voids from imperfect bonding between adjacent filaments. Thus, the FDM parts are non-homogeneous and this affects the strength and other material properties of the part. These material properties are also dependent upon the printing parameters used for to print the part, including significant influences due to the layer orientation and the bonding between adjacent filaments. This leads to an anisotropic behavior of the FDM parts. Due to the non-homogeneous and anisotropic nature of FDM parts, they deviate from their design in terms of their material properties and microstructure. Figure 3 represents a FDM part from a microstructure perspective. With more and more FDM parts being used as end use products, in performance critical applications, it is necessary to simulate and analyze these parts during design.

Finite Element Analysis (FEA) is an analysis tool that is widely used in engineering problems to analyze the structural, vibrational and thermal problems. FEA is based on the Finite Element Method (FEM) which is a numerical technique to find approximate solutions to boundary value problems for partial differential equations. In this method, a large body is divided into smaller entities known as finite elements, each represented mathematically by a set of equations. These set of equations representing the finite elements are then aggregated to form an assembly of equations that represents the larger body. Using methods from calculus, an approximate solution can be found [3]. Since FEA discretizes bodies into a continuum of finite elements to solve the problem, FEA might not be able to effectively represent the nonhomogeneous FDM bodies. Due to the difficulties in representing the microstructure and constitutive material behavior of FDM parts, FEA may not be able to predict the actual behavior of FDM parts accurately. Thus, an FEA technique that accounts for these differences, between the ideal and actual conditions relating to anisotropy and microstructure, would be able to represent the behavior of FDM parts accurately. This gives rise to a need to link local structural and bonding differences to a global anisotropic material behavior, in order to develop an accurate FEA model. More information can be found in [4]. It is therefore necessary to investigate whether FEA of FDM parts predicts their actual behavior.

In a simple FEA approach, an FDM part can be represented as a continuous part, with a linear isotropic material model. This would not be an ideal representation of FDM part behavior since FDM parts are neither homogeneous nor isotropic. Additional model complexity can be incorporated by using an orthotropic material model to take into account the anisotropy of FDM parts. In this study, the isotropic and orthotropic materials properties are also derived experimentally to closely represent the FDM part behavior. Similar approaches are found in $[5,6]$. Furthermore, a composite material model along with a composite laminae setup is used in FEA with the idea that the layered microstructure of FDM parts can be represented as a composite layup. In addition, FDM parts in this study are modeled as they are built, i.e. fiber-by-fiber and layer-by-layer. This would enable us to represent the microstructure of the FDM parts accurately. The goal of this study is to compare the simulations of the FEA approaches mentioned above with actual experimental tests of FDM parts. The design statement for this work is:

\section{FEA simulations of as-built geometries in tensile loading, using experimentally derived material models, predict actual behaviors of FDM parts.}


In this study, suitable dogbone geometry patterns are designed for the comparison of FEA and experimental results. This geometry accommodates different infill patterns such that a typical FDM part with perimeter and an infill pattern can be replicated. These geometries are printed with ABS filament and eventually tested. The printing parameters used for the parts are consistent throughout the study due to a large number of potential parameters affecting the material properties. Therefore, results of the study stand true for parts built with these parameters.

Section 2 gives a brief background about the differences in the material properties of FDM parts resulting from different printing parameters. It also discusses the work done on similar platforms, their findings and the need for further research. Section 3 talks about the methodology, i.e. specimen development, the experimental tests, FEA simulations and the process followed in this study. In Section 4 we analyze the results and discuss the findings. In Section 5, we conclude by giving remarks regarding the comparison of FEA results with experimental results and suggest areas for future research.

\section{Literature Review}

Over the years, AM technology has developed tremendously. With decrease in printing time and increase in the ease of manufacturing complex parts, more and more parts are used as end use products. Similarly, FDM parts are being used in varied sectors like aerospace, automotive, industrial and medical fields. It is possible to manufacture high end mechanically and thermally durable FDM parts with faster lead times, at the same time the process being feasible for low volume productions. Further information can be found in [7, 8 and 9]. Before comparing the FDM part simulations with actual experiments, it is necessary to understand the effects of printing parameters on the FDM parts. In addition to this, the directions of fibers lead to anisotropy. Anisotropy along with the microstructure, leads to the difference in behavior of the FDM parts as compared to homogeneous parts manufactured traditionally. It is also important to study the effect of printing parameters on the anisotropy and microstructure of the part. This would enable us to create parts with best possible finish and strength and enables us to keep the parameters consistent throughout the study. 
Table 1: Summary of research pertaining to effect of process parameters.

\begin{tabular}{|l|c|l|l|l|l|}
\hline & $\begin{array}{c}\text { Raster / Layer } \\
\text { Orientation }\end{array}$ & Temperature & $\begin{array}{c}\text { Filament } \\
\text { Width }\end{array}$ & $\begin{array}{c}\text { Air } \\
\text { gap }\end{array}$ & $\begin{array}{c}\text { Layer } \\
\text { Thickness }\end{array}$ \\
\hline Es-Said et al [12], & $\checkmark$ & & & & \\
\hline $\begin{array}{l}\text { Gajdos et al [13] } \\
\text { Bellehumeur et al [14] }\end{array}$ & & $\checkmark$ & & & \\
\hline Sun et al [15] & $\checkmark$ & $\checkmark$ & & & \\
\hline Ahn et al [16], & $\checkmark$ & $\checkmark$ & $\checkmark$ & $\checkmark$ & \\
Montero et al [17] & & & & & \\
\hline Wu et al [18], & & & & & \\
Syamsuzzaman et al [19] & & & & & \\
\hline
\end{tabular}

Zieman et al [10] and Upadhyay et al [11] discuss the anisotropic properties of FDM parts. These studies derive various material properties by varying the fiber orientation within the test part. Es-Said et al[12] presents a comprehensive analysis of the effect of different layer orientation on the material properties of the part. The authors also go on to discuss the effect of various printing parameters on the quality and strength of the part. A number of similar studies work on the documenting the effect of various process parameters on the structure and properties of the FDM parts. Table 1 lists and categorizes the literature according to the process parameters.

The important conclusions regarding the effect of each of the process parameters has been listed below:

1. Layer Orientation: Longitudinal fiber orientation $\left(0^{\circ}\right)$ results in the strongest part followed by the ' $0 \% / 90^{\circ},, 45 \%-45^{\circ}$ ' and $90^{\circ}$ orientation in case of tensile tests [16].

2. Process Temperatures (extruder and bed): That higher temperatures lead to a decrease in the percentage of non-filled area in the volume, indicating better bonding [13]. The bond quality is more affected by the extrusion temperature than the envelope temperature. The extruded filaments cannot be maintained at high temperatures long enough to enable complete bonding to occur between filaments. Therefore, finer control over the cooling conditions enables better bonding and eventually leads to better mechanical properties [14]. 
3. Air gap: Smaller air gap between adjacent filaments yields stronger parts. With smaller air gap or even a negative air gap (fiber overlap) better bonding between fibers is achieved which leads to stronger parts $[16,17]$.

4. Layer Thickness: A smaller layer thickness increases the quality and the finish of the part.

It is important to understand the material behavior of FDM parts to carry out an accurate FEA. The choice of the material model greatly affects the accuracy of the analysis, since the FDM material (ABS) exhibits isotropic behavior however, the actual part exhibits anisotropic properties. Various authors have worked on analytically deriving stress values using different material models. This can be the initial analysis that would enable us to conduct a comprehensive FEA. Zou et al [20] compares two types of material models: isotropic and transversely isotropic. Casavola et al [21] talks about the mechanical behavior of FDM parts using the Classical Laminate Theory (CLT). Orthotropic properties are derived using experimental procedures and are used to populate the CLT compliance matrix. Stress values are determined using a CLT compliance matrix and later compared with experimental results. The results from the CLT predictions are in accordance with the experimental values of stress for majority of the stress-strain curve; however, CLT results deviate close to $2 \%$ strain. Similar studies are can be found in $[22,23,24$ and 25]. A summary of the literature can be found in Table 2. 
Table 2: Summary of literature regarding analytical approaches.

\begin{tabular}{|l|l|l|}
\hline Zou et al [20] & Material Model Used & \multicolumn{1}{|c|}{ Conclusion } \\
\hline Casavola et al [21] & $\begin{array}{l}\text { Isotropic, Transversely } \\
\text { Isotropic }\end{array}$ & $\begin{array}{l}\text { 2\% difference between the 2 models. } \\
\text { Recommends using anisotropic } \\
\text { Thodel. }\end{array}$ \\
\hline Bertoldi et al [22] & Orthotropic model & $\begin{array}{l}\text { Results are in accordance with } \\
\text { experimental data for majority of the } \\
\text { stress-strain curve; Results deviate at } \\
\text { 2\% strain. }\end{array}$ \\
\hline Magalhães et al [23] & $\begin{array}{l}\text { Classical Laminate } \\
\text { Theory }\end{array}$ & $\begin{array}{l}\text { Mechanical Behavior not predicted } \\
\text { accurately using CLT; Suggest using a } \\
\text { better analytical model. }\end{array}$ \\
\hline Alaimo et al [24] & $\begin{array}{l}\text { Classical Laminate } \\
\text { Theory }\end{array}$ & $\begin{array}{l}\text { Results obtained using CLT are } \\
\text { consistent with the experimental } \\
\text { data. }\end{array}$ \\
\hline
\end{tabular}

Analytical approaches enable us to evaluate stresses only in continuous uniform areas. However, a comprehensive FEA is required to evaluate complex geometries. It is important to investigate the literature that compares FEA simulations with experimental results. Hambali et al [26] validates the deformation behavior of FDM parts with FEA using experimental parts built in different orientations. Material properties are derived and an orthotropic material model is used to simulate the three different orientations. The authors find close correlation of FEA results with experimental results; however, the accuracy of FEA depends on the build orientation. In a similar work, Hambali et al [27] validates the experimental results of FDM parts built with different build orientations using FEA. In this case, the FEA results show similar difference in results of parts with different build orientations but these results were not accurate. Domingo-Espin et al[28] analyzes the FDM parts using FEA. A constitutive orthotropic material model was used in ANSYS ${ }^{\odot}$ using a solid CAD model. These results are validated using experimental results and it is found that simulation results show similarities to experimental data. Mamadapur et al [6] also conducts a similar study with the FEA values being consistent only in case of two of the four orientations. 
Some of the literature points out the need to represent the mesostructure of FDM parts to accurately analyze them. Cuan-Urquizo et al [29] focuses on mechanical characterization of lattice structure of FDM parts using simple elastic elements to represent the infill. Villalpando et al [30] compares an FEA approach to experimental data, using models with parametric internal matrix structures under compressive loading. Rezayat et al [31] and Garg et al[32] also use a mesostructure approach to represent FDM parts. Since FDM parts are built in layers, it is hypothesized that a composite laminae approach of analysis would better represent the FDM parts. El-Gizawy et al [33] presents an integrated approach to characterize mechanical properties and internal structure of FDM parts and analyzes these using CLT. Martinez et al [34] uses a composite laminate layup using orthotropic properties in FEA using Abaqus $^{\odot}$ to predict the behavior of FDM parts. In a similar work, Sayre et al [35] also presents an FEA using two approaches: an isotropic model and a composite FE model. Even though the authors do not compare this with experimental results, the two approaches show considerable differences.

From the literature, it is evident that FEA results for FDM parts have not been consistent. It is evident that a detailed model that takes into account the microstructure and the anisotropy of FDM parts is required for precise and accurate analyses. FDM parts are usually complex with an integral infill pattern, and validating FEA approaches to accurately predict the FDM part behavior is necessary. Section 3 discusses the methodology used in this study; the FEA approaches adopted in this study and its comparison with experimental tests.

\section{Methodology}

The aim of this study is to evaluate and compare approaches to correlate the FDM parts analyzed in FEA with corresponding experimental results. A step by step approach is used in order to evaluate and compare these approaches. Suitable test geometries are printed using an FDM printer. These test specimens are tested on a tensile test bed to obtain the experimental results. The next step is to develop these geometries in CAD using as-built dimensions. The initial approach deals with generating an asbuilt CAD model of an FDM part which represents the part layer by layer as it is built, to replicate the microstructure, since FDM parts are non-homogeneous and not solid continuous bodies. Once an as-built model is created it is then simulated in a commercial FEA software using different approaches. The different approaches adopted are using isotropic, orthotropic and composite material models. These models are compared with the experimental results. An overview of the methodology, specimen development, comparison metrics and the process of the study is provided in the following subsections.

\subsection{As-built Approach}

An FDM part is manufactured in form of closely laid out filaments which gives it the fiber and layer microstructure. In order to accurately analyze these parts, it is necessary that they are correctly represented in simulations. The initial approach used in this study to develop a CAD model is to replicate the fiber structure so that we obtain an as-built CAD model. Once the part is printed, its CAD model was redesigned as an 'as-built' model using the G-code from slicer. A fiber-by-fiber and layer-by-layer model 
was created by tracing the G-code in Solidworks ${ }^{\odot}$. However, this approach led to meshing errors which are listed as follows:

1. Some of the filaments intersected adjacent features (filaments), resulting in intersecting errors within the part, rendering the CAD model useless.

2. The part with above errors eliminated caused meshing problems resulting from the misalignment of elements and nodes within the adjacent fibers in the CAD model.

3. A large part file was generated which took nine hours to mesh and more than forty hours to analyze.

Therefore, this method to model FDM parts was time prohibitive, even when intersection and alignment issues were corrected for. Therefore, a simpler approach was used to model these parts; in which the $100 \%$ infill region was modeled as a solid continuous region, whereas, the regions with infill, were traced as they are built. This approach was used to develop the geometries used in this study.

\subsection{Geometry}

This study only includes tensile tests for obtaining experimental results, therefore, the test specimen selected was a typical tensile test geometry i.e. the dogbone geometry. It has enlarged ends for gripping the specimen and a narrow middle section known as the gage section to ensure fracture is localized in the gage section only. This geometry was modeled in Solidworks ${ }^{\odot}$. The dogbone test specimens are designed similar to the specifications mentioned in ASTM D638. The maximum dimensions of the dogbone specimens $(170 \times 35 \times 2 \mathrm{~mm})$ were decided on basis of the print bed dimensions, the test bed dimensions and the grips of test frame. A general FDM part, unless otherwise specified, contains an infill pattern and thick perimeters in order to save material. Therefore, the dogbone geometries were designed to accommodate the infill patterns as well. The gage dimensions of the specimen were $(50 \times 20 \times 2 \mathrm{~mm})$ which ensured that enough features of the infill pattern were accommodated in the gage area. The infill patterns were constrained to the gage section so that the specimens would primarily elongate and fracture in the gage area. Therefore, the final test geometry had infill patterns with perimeters in the gage section and $100 \%$ elsewhere. Different types of infill patterns were used in study namely:

1. Completely Continuous (C, CX, CY, CZ)

2. Hexagonal Infill (HI)

3. Circular Straight Infill (CS)

4. Circular Packed Infill (CP)

5. Linear Straight Infill (LS)

6. Linear Crosshatch (LC)

7. Hilbert Curve (HC)

8. Infill-less (I)

9. Corresponding Continuous (CC) 
The corresponding continuous geometry has a continuous gage section such that it is equivalent in volume in the gage section with the infill pattern. This leads to a gage section with the same rectangular dimensions but with a lesser thickness. In addition to this a completely continuous (C) sample was also created which was used to derive the isotropic material properties in study. In order to derive the orthotropic material properties, the continuous samples were built in three mutually orthogonal directions: $X, Y$, and $Z$ to obtain three sets of samples: $C X, C Y$, and $C Z$. Figures 4 and 5 show the $H I$ and $C P$ samples. Rest of the samples can be found in Appendix A.

\subsection{Assumptions}

A number of assumptions that were made in the study have been stated below:

- Over the course of the study, different ABS spools were used for printing the test specimens. It is assumed that the material from the different spools is consistent with the material properties.

- The laboratory operation temperature was consistent throughout the study and therefore, the environment is not considered as a significant factor that affects the printing or testing.

- Any errors in clamping the specimens were considered to be randomly distributed.

\subsection{Printer and printing parameters}

Once a CAD model is created, it is converted into an STL file format for the slicing software to be prepared for printing. The slicing software creates a G-code file for the printer. The printer used for this study is MakerBot ${ }^{\odot}$ Replicator $2 X$. The slicing software used was Slic $3 r^{\odot}$. However, in case of (C) specimens that were used to derive orthotropic material properties, 'Simplify $3 \mathrm{D}^{\odot}{ }^{\odot}$ ' was used in order to specify the filament directions.

The printing parameters were kept as consistent as possible throughout the study. The printer's heated bed temperature for all the specimens was $130^{\circ} \mathrm{C}$. All the specimens were printed using white ABS with an extruder temperature of $230^{\circ} \mathrm{C}$. The print parameters were finalized after a number of iterations that resulted in the most consistent specimens. The parts were printed without a raft or support. The circular specimens were printed with a layer height of $0.4 \mathrm{~mm}$, whereas the rest of the specimens were printed with a $0.2 \mathrm{~mm}$ layer height. The specimens were printed with a $100 \%$ diagonal $\left(45^{\circ} /-45^{\circ}\right)$ infill pattern in the solid region, since the infill pattern in the gage section was already modeled in CAD. The specimens used for deriving the material properties had the same print settings as those of the other geometries. The samples used for deriving the isotropic material properties were printed with a $100 \%$ diagonal $\left(45^{\circ} /-45^{\circ}\right)$ infill pattern as well. In order to derive the orthotropic properties, the continuous sample was built in three mutually orthogonal directions with fibers in the longitudinal $\left(0^{\circ}\right)$ direction.

\subsection{Tensile Tests}

In order to compare the accuracy of finite element analyses experimental data was necessary. Therefore, tensile tests are conducted on all the samples. The tests were performed on 'Modular under Microscope 
Mechanical Test System $-\mu \mathrm{TS}^{\prime}$ by Psylotech ${ }^{\odot}$. The test specimens were attached using clamping grips. A displacement controlled tensile test was performed at uniform rate of $50 \mu / \mathrm{s}$. The test specifications were similar for all the specimens. The test software recorded the displacement at every time step and the force required to pull the test sample at that corresponding displacement. This data is further post processed to obtain stress and strain using the appropriate gage length dimensions. To ensure repeatability, a sample set of 20 specimens was used for each geometry.

The continuous samples were used to derive the mechanical properties for the study. For deriving the isotropic properties, the (C) sample was subjected to tensile tests. Stress values were calculated using force and cross-sectional area, whereas strain values were calculated using the displacement and the gage length. This stress-stain curve is used to calculate the elastic modulus which is used in simulations. Similarly, in order to derive the orthotropic properties, three sets of different test specimens were built in three mutually orthogonal directions. This enabled us to calculate the elastic moduli in each of the three orthogonal directions.

\subsection{FEA Simulations}

Each of the specimens were modeled in CAD as as-built models; any changes in dimensions after manufacturing the samples are taken into account. Further, the experimental tensile tests are simulated using these as-built CAD models in a commercial FEA software. Two FEA solvers are used: ANSYS ${ }^{\odot}$ and Abaqus $^{\odot}$. To simulate the tensile tests, a transient structural analysis is conducted on the as-built CAD models. A displacement controlled tensile test is setup wherein the displacement readings from the experiments are used as input displacements with one shoulder end fixed.

Four different FEA models are used; each one being more complex than the previous one to increase the fidelity of FEA model to the actual behavior. In the first model or approach, an isotropic material model is used for FEA. The material properties used are the material properties of homogeneous bulk ABS material [36]. This model will be called the Bulk Isotropic Model (BIM). In the second approach, to increase the fidelity of FEA, derived properties of the continuous FDM samples (C) are used. These samples are used along with an isotropic material model. The elastic modulus is derived experimentally, and Poisson's ratio is taken from engineering catalogs [36] due to lack of test equipment. This model is called as Derived Isotropic Model (DIM). Table 3 lists all the derived material properties.

To further take into consideration the anisotropy of FDM parts, an orthotropic material model was also applied. The elastic properties are derived experimentally using CX, CY and CZ samples and used along with an orthotropic material model. This approach is known as the Orthotropic Derived Model (ODM). The fourth approach uses a composite layup to define the finite element model. Since the FDM part is built in layers, a composite laminae approach may be better able to represent the behavior of FDM part. In this type of analysis, the part is divided into a set of plies or laminae, stacked together to form a composite part. This enables us to set fiber orientations in individual fiber lamina, so that the directional fiber layup can be accounted for in the model. This approach is called as Composite Lamina Model (CLM). Each of 
the as-built models are divided into a number of layers with each layer being as thick as the layer height of the part. The models built with $0.2 \mathrm{~mm}$ layer height have a ply thickness of $0.2 \mathrm{~mm}$ with 10 layers stacking up to the $2 \mathrm{~mm}$ height of the part. Similarly, $0.4 \mathrm{~mm}$ layer height parts have a ply thickness of $0.4 \mathrm{~mm}$. The fiber directions are specified as $45^{\circ} /-45^{\circ}$ every alternate layers, just as the actual parts. The CLM is performed only in Abaqus ${ }^{\odot}$, since ANSYS $^{\odot}$ only permits shell models for composite analysis.

Since the infill patterns have intricate features with thin wall structures, a refined mesh is used. Quadratic tetrahedral elements are used in all of the specimens except CS and CP. A similar mesh is replicated in Abaqus $^{\odot}$, so that the analysis from the solvers is comparable. Mesh convergence is performed to ensure appropriate suitable mesh density. However, with the CLM, a tetrahedral element mesh is not possible and therefore hexahedral brick elements were used. Normal stresses are calculated and are used as metrics for comparison with experimental and FEA results.

Table 3: Orthotropic material properties derived from experimental testing.

\begin{tabular}{|c|c|c|}
\hline Models used & Derived Material Property of ABS & Value \\
\hline BIM & Young' Modulus bulk ABS & $2 \mathrm{GPa}$ \\
\hline DIM & Young' Modulus for $45 \% /-45^{\circ}$ (C) & $1 \mathrm{GPa}$ \\
\hline BIM/DIM/ODM/CLM & Poisson's Ratio $\left(v_{x y}=v_{x y}=v_{x y}\right)$ & 0.394 \\
\hline \multirow{7}{*}{ ODM/CLM } & Young's Modulus in X $\left(E_{x}\right)$ & $1.1 \mathrm{GPa}$ \\
\hline & Young's Modulus in $Y\left(E_{y}\right)$ & $0.9 \mathrm{GPa}$ \\
\hline & Young's Modulus in $Z\left(E_{2}\right)$ & $0.88 \mathrm{GPa}$ \\
\hline & Shear Modulus $\left(\mathrm{G}_{x y}\right)$ & $0.39 \mathrm{GPa}$ \\
\hline & Shear Modulus ( $\left.\mathrm{G}_{\mathrm{yz}}\right)$ & $0.32 \mathrm{GPa}$ \\
\hline & Shear Modulus $\left(G_{x z}\right)$ & $0.31 \mathrm{GPa}$ \\
\hline & Density & $1020 \mathrm{~kg} / \mathrm{m}^{3}$ \\
\hline
\end{tabular}

\section{Results}


The printed geometries are shown in Figure 4. The fractured geometries are shown in Figure 6. The results of the material properties have already been mentioned in Table 3 . The experimental stress vs strain values are plotted and used as reference. The stress values calculated for this comparison are stress values across the least cross sectional area of each of the infill specimens. Similarly, the stress values at the same cross-section from each of the FEA simulations are also plotted. The stress-strain plots have been truncated to show only the elastic region, as a non-linear plastic analysis was not conducted. The FEA stress concentration plots were similar for all the models used with only the magnitude being different, hence, only a single stress plot per sample is shown. Also, the FEA results for a

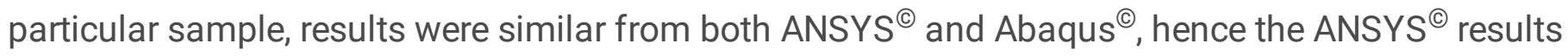
represent the FEA simulation results in the comparison. Separate results are plotted and presented wherever necessary.

The first specimen for discussion is the completely continuous (C) specimen. Figure 6 shows a stressstrain plot of the experimental and FEA results of (c) specimen. We can see a cone of results. The blue line shows the experimental results. We can see that BIM has over-predicted the results, whereas DIM has under predicted the results. We see a slight improvement in the ODM results as compared to the DIM results. However, CIM results show no improvement over the results from ODM. Even though all the models showed large errors, BIM showed the least erroneous results with about $25 \%$ of error between the simulations and experimental results. From the FEA stress plot in Figure 7, we can see that FEA predicted the highest stress concentrations in the gage section, which is where the actual part fractured. However, whether FEA can predict the zig-zag nature of the fracture is difficult to say without further analysis.

Figure 8 shows the stress plot for the CP specimens. The blue line represents the experimental results. In this case the BIM results, again, over-predicted the results and by a huge margin of about $50 \%$. However, the DIM results, depicted by the yellow line, were very close to the experimental results showing about $3 \%$ to $10 \%$ errors which are acceptable results considering the fact that a non-homogeneous FDM part is analyzed. It is evident that, the ODM stress results (from ANSYS ${ }^{\circledR}$ ) were almost completely coincidental with the experimental results for majority of the stress-strain curve. It is important to note in this case that the ODM results from Abaqus ${ }^{\complement}$ did not coincide but deviated by as much as $20 \%$. Thus, we see a difference between the results from different solvers, with error between the solver results being more the error between simulation and experimental results. The CLM results deviated even more the DIM results. Also, the FEA stress plots showed high stress concentrations in the least cross-sectional areas, which is where they fractured. Figure 9 shows the comparison between the stress contour plot and the fracture pattern. Thus, in case of CP specimens FEA accurately predicted the magnitude as well as the locations of stresses. The CS specimen results were similar to the CP specimens, i.e. the ODM and the DIM results were within acceptable deviations from the experimental results. However, the BIM model over predicted by a large margin.

Figure 10 shows the stress-strain plots for the experimental and FEA results and Figure 11 shows the comparison between the stress contour plot and the fracture pattern. In case of the I specimens, all the FEA models including the BIM under-predicted the results. However, BIM results were accurate with 
acceptable errors of about $5 \%$. The models using derived properties however, under-predicted by as much as $50 \%$. The FEA stress plots shows the stress concentrations where the actual fracture occurred. Figure 12 shows a bar graph of stress results from experimental and finite element analyses for all the samples.

To visualize the stress value bars representing the different simulations for each of the specimen geometry, the bars are consistently ordered from left to right: Bulk Isotropic Model, Experimental Results, Derived Isotropic Model, Orthotropic Derived Model, and the Composite Lamina Model. The HC specimen was similar to the I specimen in the sense that, the BIM results were closer than the results from using derived properties. In case of the $\mathrm{HI}$ specimen, all the models showed considerable differences in results. In case of both the linear samples, ODM results were the closest even though ODM under-predicted by about $20 \%$ to $25 \%$. The $\mathrm{CHI}$ specimen is the only case in which the CLM results were more accurate than the ODM results. The CLM results were almost completely coincidental throughout the stress-strain curve. FEA also predicted the stress concentration in the gage section which is where the samples fractured. However, whether or not FEA will be able to predict the diagonal nature of the fracture is difficult to state without further analyses. FEA stress plots in case of HI, LS and LC specimens predicted the location of fracture, however, it was not exhaustive. FEA simulations were unable to predict the fracture in the infill region in case of $\mathrm{HI}, \mathrm{LS}$ and $\mathrm{LC}$ specimens, which is region that fractured first in experiments. On the contrary, these regions were shown as regions with least stress concentrations. Thus, we see ambiguity with the FEA results for different specimens.

Summarizing the observations, we can say that BIM generally over-predicted the results implying that the part is stronger than it actually was in physical tests. The BIM results showed deviations of up to $75 \%$ with respect to experimental results. However, for $\mathrm{HC}$ and I specimens, the BIM results had acceptable errors. BIM results were also more accurate than the rest of the models in case of these two specimens. On the other hand, the derived properties' models (DIM, ODM and CLM) consistently under-predicted the results. The ODM predicted the results most accurately as compared to the other models. DIM results were within acceptable deviations in case of $\mathrm{CP}$ and CS specimens. Other specimens witnessed larger deviations ranging from $15 \%$ to $30 \%$ with the errors being as high as $50 \%$ in case of $\mathrm{HC}$ and I specimens. It is important to note that, ODM results proved only a slight improvement over the DIM results, despite increased computational costs. This is due to the fact that the specimens have been analyzed only for uniaxial tensile tests (in $x$ direction). Therefore, even the orthotropic analyses are primarily governed by the elastic modulus in $x$ direction. Recalling the values from Table 4, $E_{x}=1.1 \mathrm{GPa}$ and $\mathrm{E}=1 \mathrm{GPa}$ (Elastic Modulus for the isotropic model), the slight difference in the elastic moduli from the two sample resulted in only a slight improvement of results even when an orthotropic material model was used. However, in case of a more complex, multi-directional loading, the orthotropic model might show considerable improvement as compared to the isotropic model. We also observed difference in results of different solvers in case of certain specimens.

The more detailed CLM showed no improvement in the results as compared to the ODM. The only specimen for which the CLM results were better than the ODM results was the $\mathrm{CHI}$ specimen. For rest of the specimens, the ODM results were more accurate than their CLM counterparts. In addition to this, CLM 
analysis showed large deformations in certain cases (LS and LC) which can be attributed to element meshing errors. Another explanation for CLM showing inferior results can be the type of analysis, since in case of CLM, each layer is considered as a 2D lamina or a planar surface and meshed with an element thickness. In case of ODM analyses, the model is considered as a solid model with orthotropic material properties and assigned a particular material orientation, which is a more accurate representation of the structure. Laminar theory also assumes perfect bonding between each layer of composite; however, this is not the case in actual scenario and can be a reason for the divergence from experimental data. CLM also takes a longer time to complete the analysis as compared to ODM and other models yet fails to predict the results as accurately as ODM. Therefore, using a composite model for analyzing FDM parts under tensile loading is not recommended or not necessary.

The stress plots of a particular geometry for the different models were very similar, with only magnitude being the difference. FEA models were accurately able to predict the stress locations in most cases. However, it did not predict all the fracture locations in certain cases like the HI, LC and LS specimens (FEA failed to show the fracture in the infill regions was).

Thus, we see that FEA results were highly accurate in certain cases, and in other cases, showed large deviations in results as compared to the experimental results. We observe that a given FEA model predicts the same test differently, and hence there is no certainty to propose a correction factor for these errors. The accuracy of the results is different with different geometries. The positive as well as negative deviations from the experimental results renders us to state that FEA is unreliable to predict the analysis of FDM parts in tensile loading. In the next section, we discuss the conclusion and state the scope for future research.

\section{Conclusion And Future Work.}

\subsection{Conclusion}

A comparative study of the FEA simulations and experimental tests was performed using specimens with different infill geometries. The use of different infill geometries alters the time between the printing of adjacent fibers in both the intralayer and interlayer situations. Due to changes in the timing between the printing of adjacent layers, we see differences in the bond strengths achieved between adjacent fibers (intralayer bonding) and between fibers in subsequent layers (interlayer bonding). Consequently, FEA models using material properties derived from bulk properties may be unreliable predictors of the strength of FDM parts.

If bulk material properties are unreliable, perhaps experimentally derived properties of as-built samples can produce a more effective model. Multiple specimens were printed, experimentally tested and that data was used to generate an isotropic model of the material behavior. This model was again used in a set of FEA models, but still did not reliably produce predictive results. 
Further experimental efforts to produce an orthotropic derived material model (ODM) that better accounts for the differences in fiber orientation by accounting for intralayer versus interlayer bonding strengths between adjacent fibers produced better and more consistent FEA results. A different material modeling approach employing CLM was also applied, but these models did not better the results as compared to the orthotropic model. The CLM results were inferior to the ODM results, CLM analyses produced increasing meshing errors, large deformations and consistently required significantly longer analysis time as compared to the ODM analyses. Therefore, there is no need to resort to a complex composite model while analyzing FDM parts. It can be concluded that, from the four models used, the higher fidelity Orthotropic Material Model (ODM) best represents the non-isotropic FDM parts.

Overall, the FEA results were inconsistent and therefore unreliable predictors of the behavior of the FDM parts. For different modeling approaches, FEA models may over- or under-predict the behavior of the actual FDM parts. The results appear to be increasingly unreliable as the number of fibers within the cross-section of the part becomes smaller. Large cross-sections with many fibers to provide intra- and inter-layer bonding behave much more like isotropic bulk material specimens. Unfortunately, the desire to reduce printing time, part weight, and material required all lead to FDM part designs where infill patterns and parts with cross-sections that only require a couple of fibers are generally desirable. These structures produced the least reliable FEA predictions.

Furthermore, analysis of the predicted failure locations within the samples was also not reliable. Some specimens were accurately predicted, while others were not. In general, it appears that as the infill geometry becomes more complex, and therefore, the fiber patterns become more significant in the analysis, that FEA is less able to predict the behaviors of the parts.

Finally, the magnitude of the prediction errors varied not only with material model, but also with the infill geometry itself. This pattern clearly suggests that not only are the intra- and inter-layer bonding behaviors, as well as the relationship between fiber size and part cross-sectional area, important to the accurate analysis of FDM parts, but the actual infill geometries play a role as well. The digital heritage of FDM parts as opposed to the continuous nature of traditionally manufactured parts proves to be challenging to existing FEA modeling approaches.

\subsection{Future Scope}

This research provides a significant contribution by demonstrating that the nonlinear anisotropic material properties as well as the discontinuous nature of FDM parts produces significant reliability considerations for the design of FDM parts. Further experimental work should be conducted to examine these behaviors not only in tensile testing, but in other uni- and multi-axial load conditions, as well as to examine the effect of the additive manufacture process selected for part production. The authors believe that the FDM process suffers from intra- and inter-layer bonding effects, but also suspect that other additive manufacturing processes will generate similar effects. 
In addition, these research results suggest that alternatives to FEA modeling of additively manufactured parts should be developed. The data from this research indicates that there are material anisotropic effects, geometric effects, and manufacturing toolpath effects that affect the ultimate material properties of the parts. A model formulation such as that made possible with Discrete Element Methods (DEM) may yield results that have more reliable predictive value. DEM is a numerical approximation method for mechanics of continuous and discontinuous models, which is based on an interacting system of particles [39]. The material is modelled as an assembly of rigid particles and the interaction between each particle is explicitly considered to evaluate the stress-strain results. Steuben et al [39] discusses a Discrete Element Method to analyze the particle based AM methods. Such a system of discrete rigid particles might be better able to link the material model and the toolpath dependencies associated with an FDM part.

There is a clear need to investigate and develop better technologies to better represent the microstructural and material behavior of FDM (eventually AM) parts. With the increasing use of AM parts for functional applications, research regarding simulating these parts under the actual loading condition is necessary.

\section{Declarations}

\section{Acknowledgements}

The work presented in this paper is developed from the thesis work of Baikerikar [40]. The authors wish to gratefully acknowledge the support of the Clemson University Mechanical Engineering Department, and Dr. Garrett Pataky for providing access to the load testing equipment in his laboratory.

\section{Compliance with Ethical Standards}

All research was conducted according the ethical standards and guidelines established by Clemson University.

\section{Consent to Participate}

No human or animal subjects were used in this study.

\section{Consent to Publish}

By submission, the authors grant consent to publish the results of their research.

\section{Authors Contributions}

Both authors have made substantial contributions to this research.

\section{Funding}


Support for this research was provided by Clemson University through the Department of Mechanical Engineering, with access to load testing equipment provided by Dr. Garrett Pataky of the Department of Mechanical Engineering at Clemson University.

\section{Conflicting/Competing Interests}

All authors certify that they have no affiliations with or involvement in any organization or entity with any financial interest or non-financial interest in the subject matter or materials discussed in this manuscript.

\section{Availability of data and materials}

Data concerning this research is available through Clemson University by request to the corresponding author.

\section{References}

1. Gibson I, Rosen DW, Stucker B (2010) Additive manufacturing technologies. Springer, New York 2. Wohlers T, "U.S. Manufacturing Competitiveness Initiative Dialogue," presented at the Council on Competitiveness, Oak Ridge, TN, 18-Apr-2013

3. Reddy JN (2006) An Introduction to the Finite Element Method (Third Ed.). McGraw-Hill. ISBN 9780071267618

4. http://www.padtinc.com/blog/the-focus/fused-deposition-modeling-fdm-properties-amicromechanics-perspective

5. http://

6. Mamadapur MS (2007) Constitutive modeling of fused deposition modeling acrylonitrile butadiene styrene (ABS) (Doctoral dissertation, Texas A\&M University)

7. https://www.stratasysdirect.com/solutions/fused-deposition-modeling/

8. http://proto3000.com/fused-deposition-modeling-solutions-fdm-3d-printing-applications.php

9. http://www.stratasys.com/resources/case-studies/defense

10. Ziemian C, Sharma M, Ziemian S (2012) Anisotropic mechanical properties of ABS parts fabricated by fused deposition modelling. INTECH Open Access Publisher

11. Upadhyay K, Dwivedi R, Singh AK (2017) Determination and Comparison of the Anisotropic Strengths of Fused Deposition Modeling P400 ABS. In Advances in 3D Printing \& Additive Manufacturing Technologies (pp. 9-28). Springer Singapore

12. Es-Said OS, Foyos J, Noorani R, Mendelson M, Marloth R, Pregger BA (2000) Effect of layer orientation on mechanical properties of rapid prototyped samples. Mater Manuf Processes 15(1):107-122

13. Gajdoš I, Slota J (2013) Influence of printing conditions on structure in FDM prototypes. Technical Gazette 20(2):231-236 
14. Bellehumeur C, Li L, Sun Q, Gu P (2004) Modeling of bond formation between polymer filaments in the fused deposition modeling process. Journal of Manufacturing Processes 6(2):170-178

15. Sun Q, Rizvi GM, Bellehumeur CT, Gu P (2008) Effect of processing conditions on the bonding quality of FDM polymer filaments. Rapid Prototyping Journal 14(2):72-80

16. Ahn SH, Montero M, Odell D, Roundy S, Wright PK (2002) Anisotropic material properties of fused deposition modeling ABS. Rapid prototyping journal 8(4):248-257

17. Montero M, Roundy S, Odell D, Ahn SH, Wright PK (2001) Material characterization of fused deposition modeling (FDM) ABS by designed experiments. Society of Manufacturing Engineers, 10(13552540210441166)

18. Wu W, Geng P, Li G, Zhao D, Zhang H, Zhao J (2015) Influence of layer thickness and raster angle on the mechanical properties of 3D-printed PEEK and a comparative mechanical study between PEEK and ABS. Materials 8(9):5834-5846

19. Syamsuzzaman M, Mardi NA, Fadzil M, Farazila Y (2014) Investigation of layer thickness effect on the performance of low-cost and commercial fused deposition modelling printers. Mater Res Innovations 18(sup6):S6-S485

20. Zou R, Xia Y, Liu S, Hu P, Hou W, Hu Q, Shan C (2016) Isotropic and anisotropic elasticity and yielding of 3D printed material. Composites Part B: Engineering 99:506-513

21. Casavola C, Cazzato A, Moramarco V, Pappalettere C (2016) Orthotropic mechanical properties of fused deposition modelling parts described by classical laminate theory. Materials Design 90:453458

22. Bertoldi M, Yardimci MA, Pistor CM, Guceri SI, Sala G (1998) Mechanical characterization of parts processed via fused deposition. In Proceedings of the 1998 solid freeform fabrication symposium (pp. 557-565)

23. Magalhães LC, Volpato N, Luersen MA (2014) Evaluation of stiffness and strength in fused deposition sandwich specimens. Journal of the Brazilian Society of Mechanical Sciences Engineering 36(3):449-459

24. Alaimo G, Marconi S, Costato L, Auricchio F (2017) Influence of meso-structure and chemical composition on FDM 3D-printed parts. Composites Part B: Engineering 113:371-380

25. Dutta D (1999) Deposition strategies and resulting part stiffnesses in fused deposition modeling. Ann Arbor 1050:48109

26. Hambali RH, Celik HK, Smith PC, Rennie AEW, Ucar M (2010, September) Effect of build orientation on FDM parts: a case study for validation of deformation behaviour by FEA. In IN: Proceedings of iDECON 2010-international conference on design and concurrent engineering, Universiti Teknikal Malaysia Melaka, Melaka (pp. 224-228)

27. Hambali RH, Smith P, Rennie AEW (2012) Determination of the effect of part orientation to the strength value on additive manufacturing FDM for end-use parts by physical testing and validation via three-dimensional finite element analysis. International Journal of Materials Engineering Innovation 3(3-4):269-281 
28. Domingo-Espin M, Puigoriol-Forcada JM, Garcia-Granada AA, Llumà J, Borros S, Reyes G (2015) Mechanical property characterization and simulation of fused deposition modeling Polycarbonate parts. Materials Design 83:670-677

29. Cuan-Urquizo E, Yang S, Bhaskar A (2015) Mechanical characterisation of additively manufactured material having lattice microstructure. In IOP Conference Series: Materials Science and Engineering (Vol. 74, No. 1, p. 012004). IOP Publishing

30. Villalpando L, Eiliat H, Urbanic RJ (2014) An optimization approach for components built by fused deposition modeling with parametric internal structures. Procedia CIRP 17:800-805

31. Rezayat H, Zhou W, Siriruk A, Penumadu D, Babu SS (2015) Structure-mechanical property relationship in fused deposition modelling. Mater Sci Technol 31(8):895-903

32. Garg A, Bhattacharya A (2017) An insight to the failure of FDM parts under tensile loading: finite element analysis and experimental study. Int J Mech Sci 120:225-236

33. El-Gizawy AS, Corl S, Graybill B (2011, July) Process-induced properties of fdm products. In Proceedings of the ICMET, International Conference on Mechanical Engineerings and Technology Congress \& Exposition

34. Martínez J, Diéguez JL, Ares E, Pereira A, Hernández P, Pérez JA (2013) Comparative between FEM models for FDM parts and their approach to a real mechanical behaviour. Procedia Eng 63:878-884

35. Sayre III, R (2014) A Comparative Finite Element Stress Analysis of Isotropic and Fusion Deposited 3D Printed Polymer (Doctoral dissertation, Rensselaer Polytechnic Institute)

36. https://plastics.ulprospector.com/generics/1/c/t/acrylonitrile-butadiene-styrene-abs-propertiesprocessing

37. Steuben JC, lliopoulos AP, Michopoulos JG (2016) Implicit slicing for functionally tailored additive manufacturing. Comput Aided Des 77:107-119

38. Michopoulos JG, Hermanson JC, Iliopoulos A (2014) Advances on the constitutive characterization of composites via multiaxial robotic testing and design optimization. Advances in computers information in engineering research 1:73-95

39. Steuben JC, Iliopoulos AP, Michopoulos JG (2016) Discrete element modeling of particle-based additive manufacturing processes. Comput Methods Appl Mech Eng 305:537-561

40. Baikerikar PJ (2017) Comparison of As-Built FEA Simulations and Experimental Results for Additively Manufactured Dogbone Geometries (Master's Thesis). Department of Mechanical Engineering, Clemson University, Clemson, SC. May 2017

\section{Figures}




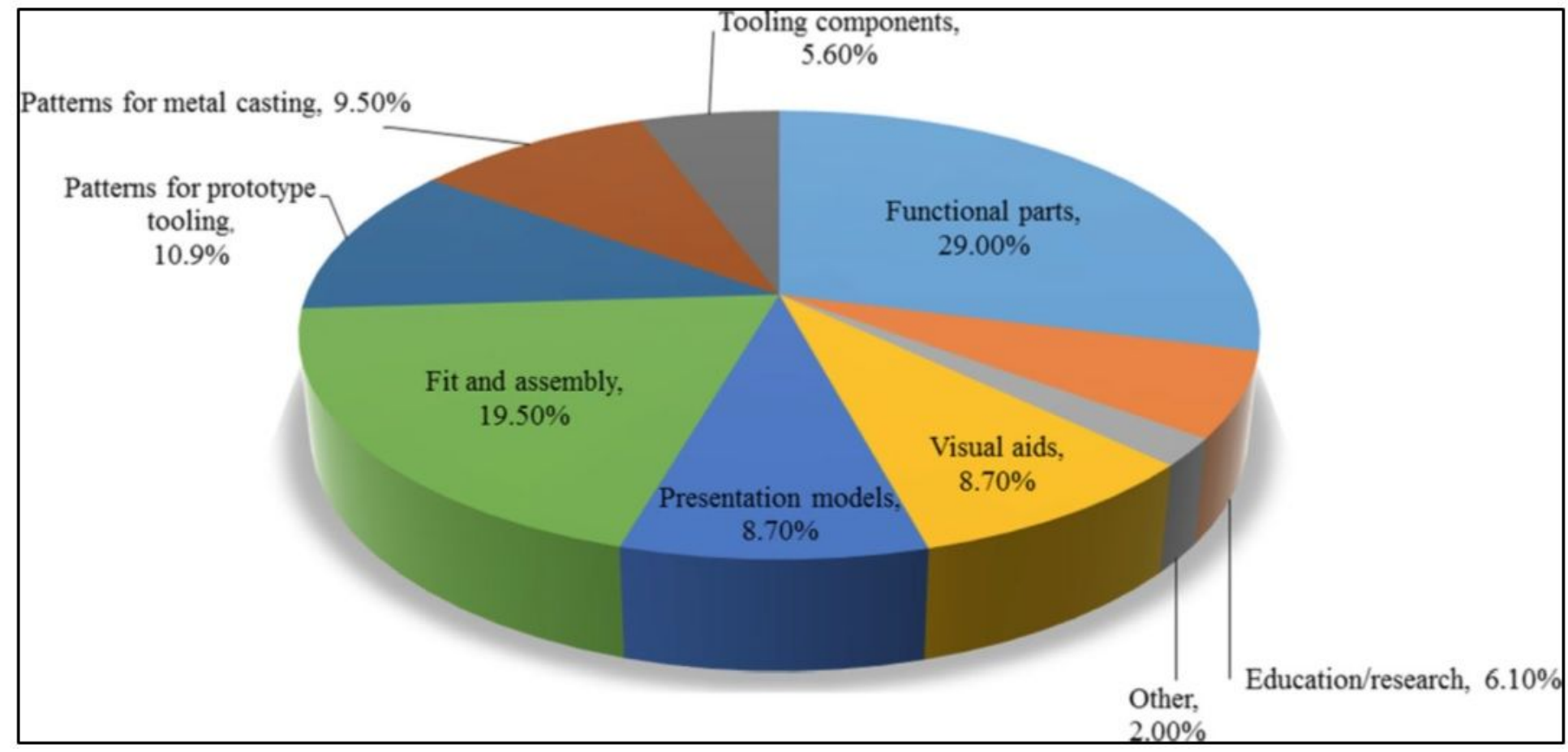

\section{Figure 1}

Chart showing applications of AM [2]. 


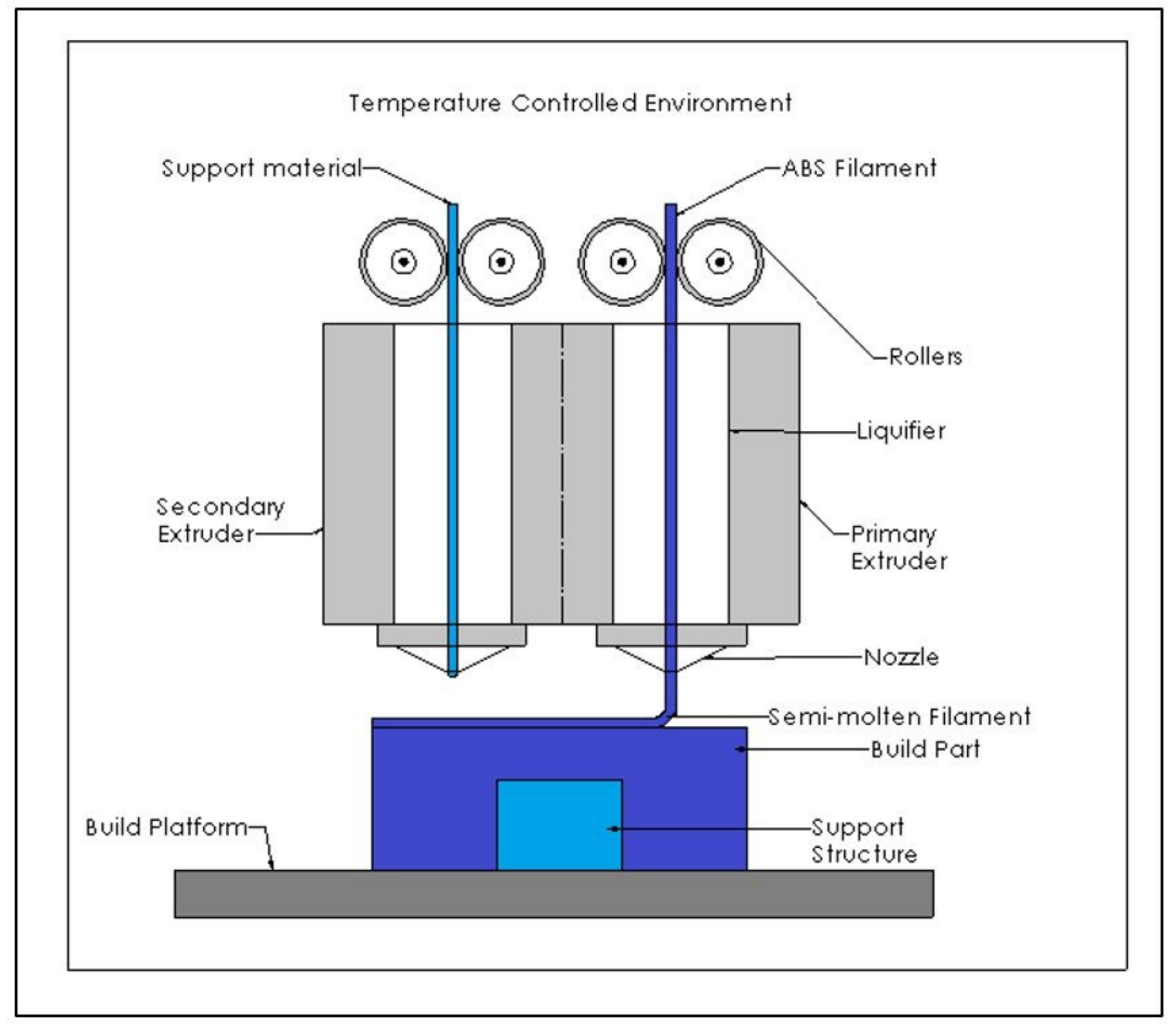

Figure 2

Fused Deposition Modelling process representation. 


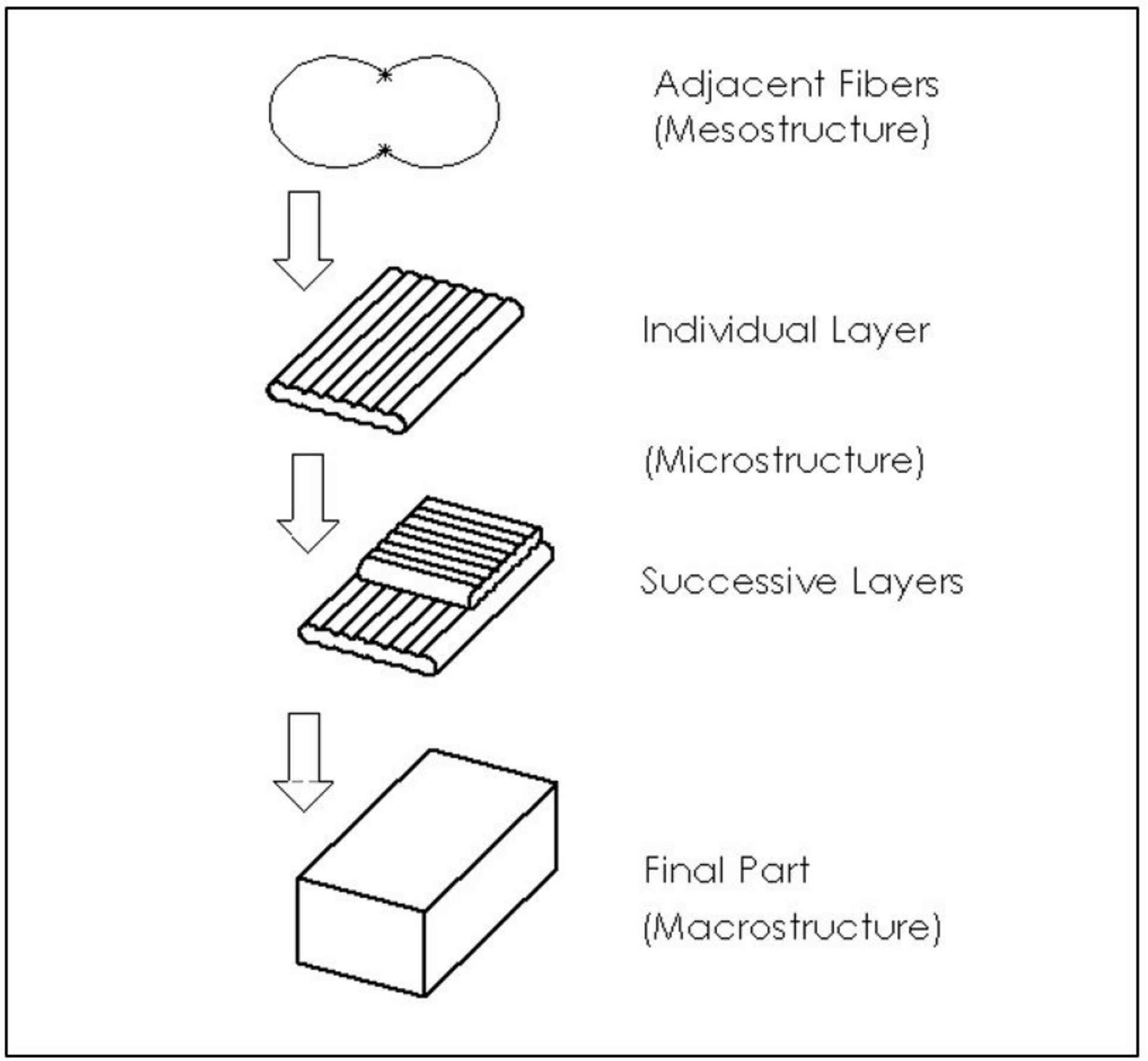

Figure 3

Multiscale levels of FDM part. 


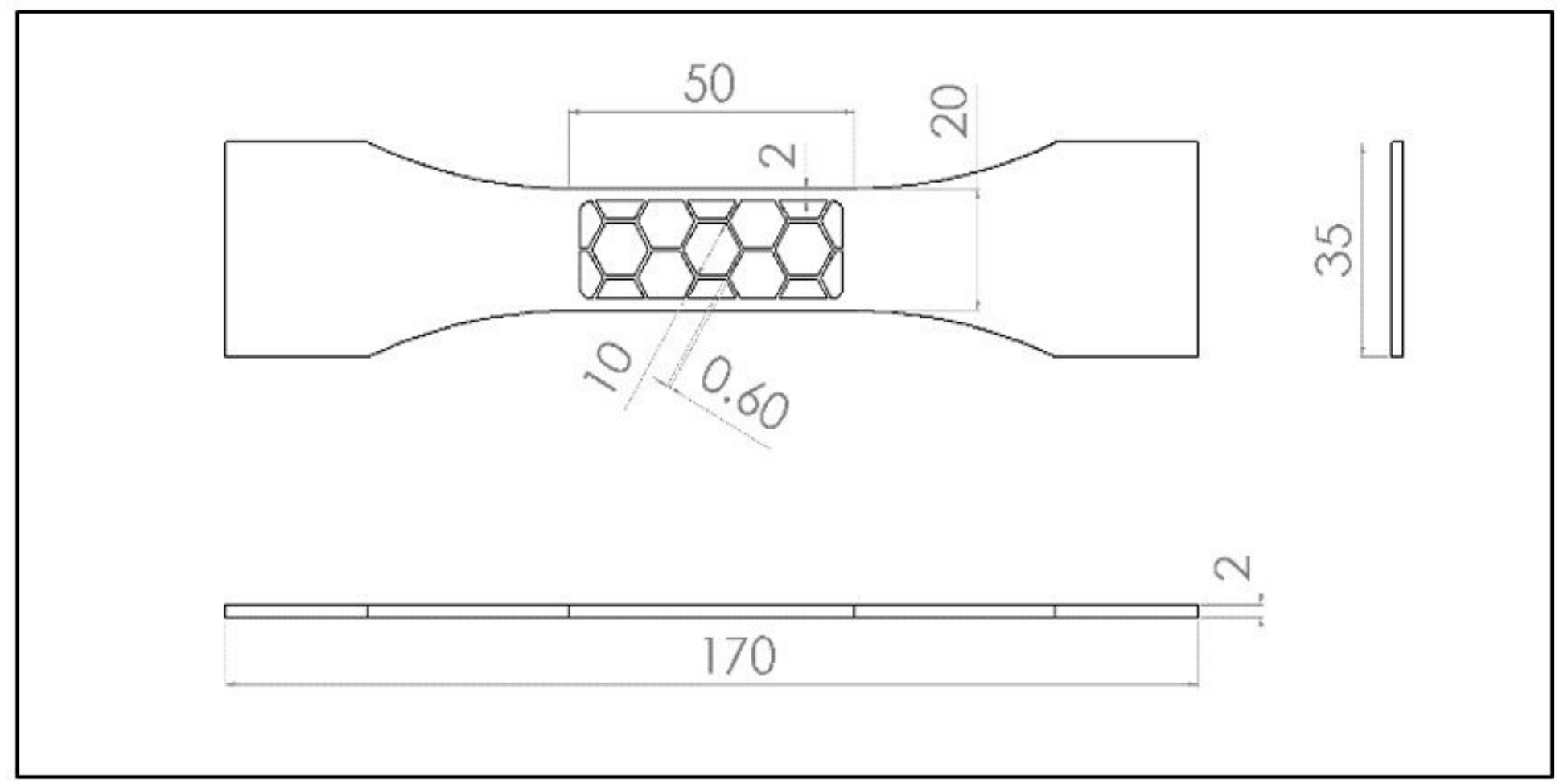

Figure 4

Hexagonal Infill (HI) specimen.

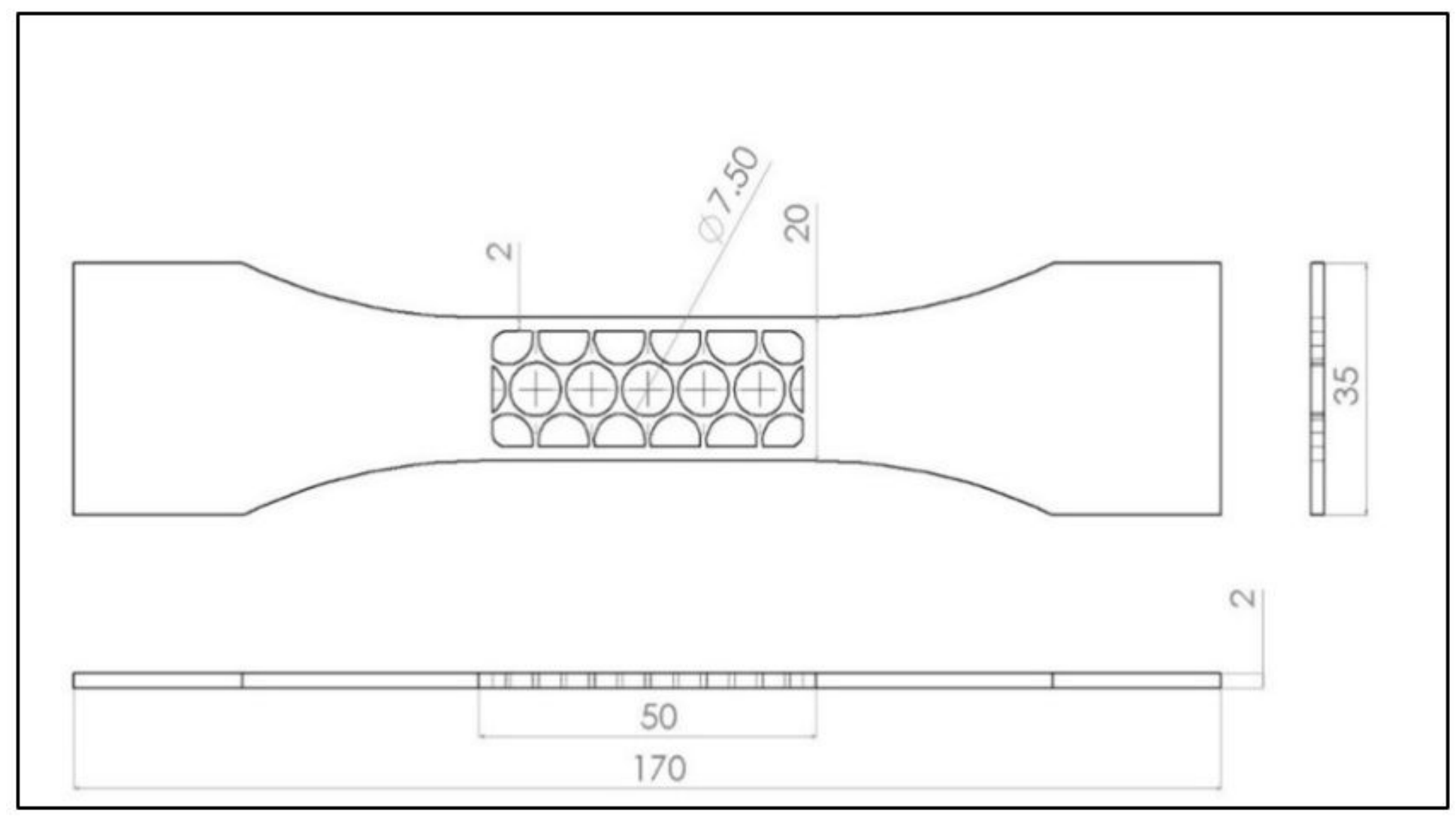

Figure 5

Page 24/28 
Circular - Packed Infill (CP) specimen.

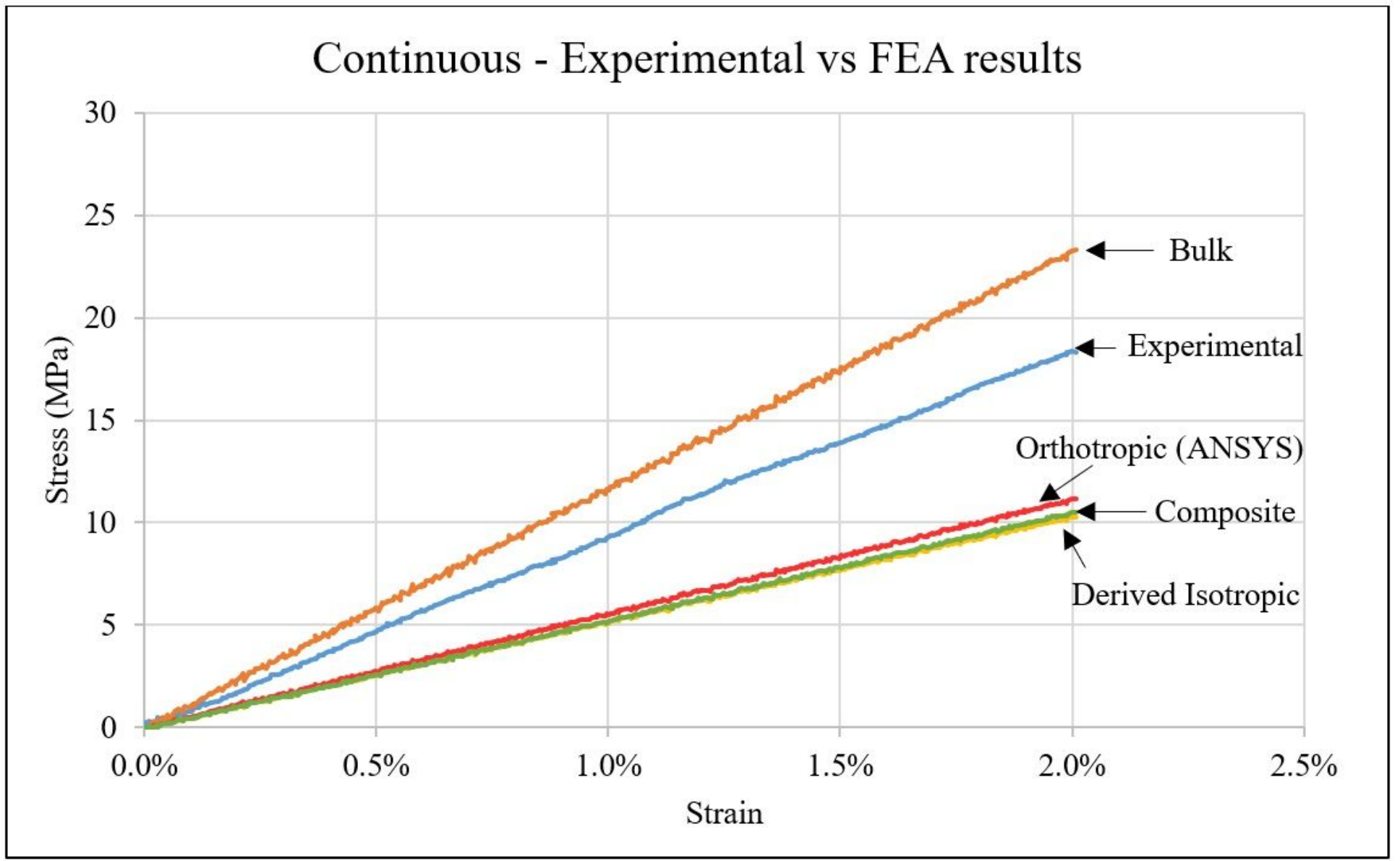

Figure 6

Stress-strain plot for C: Experimental and Simulated results.

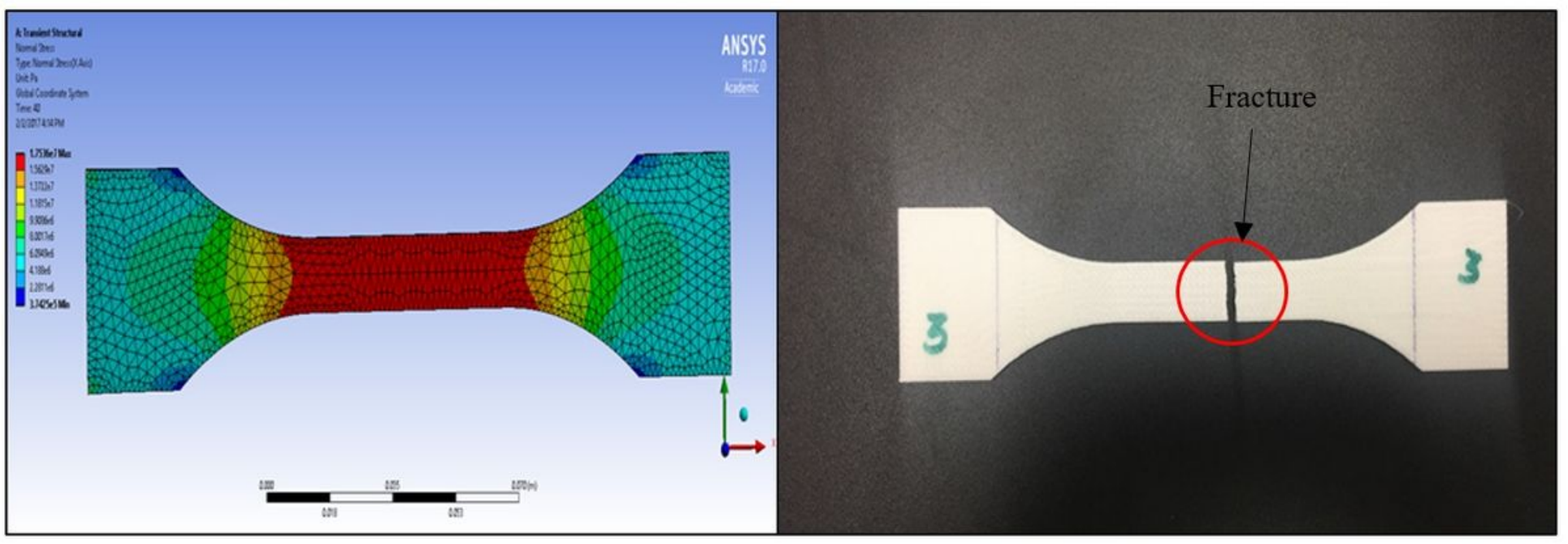

Figure 7

Stress plot for C: left - FEA contour plot, right - actual fractured part. 


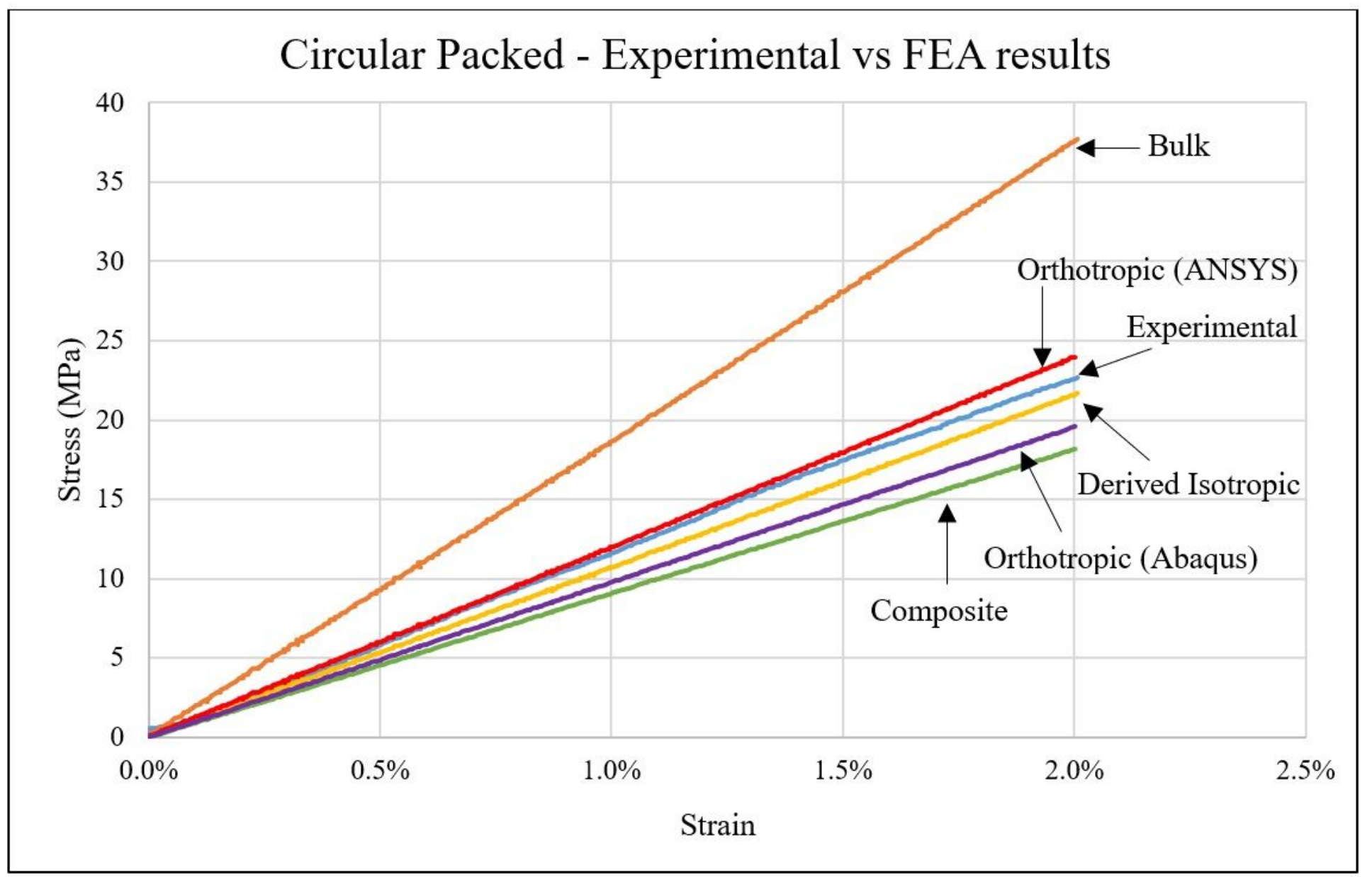

Figure 8

Stress-strain plot for CP: Experimental and Simulated results.

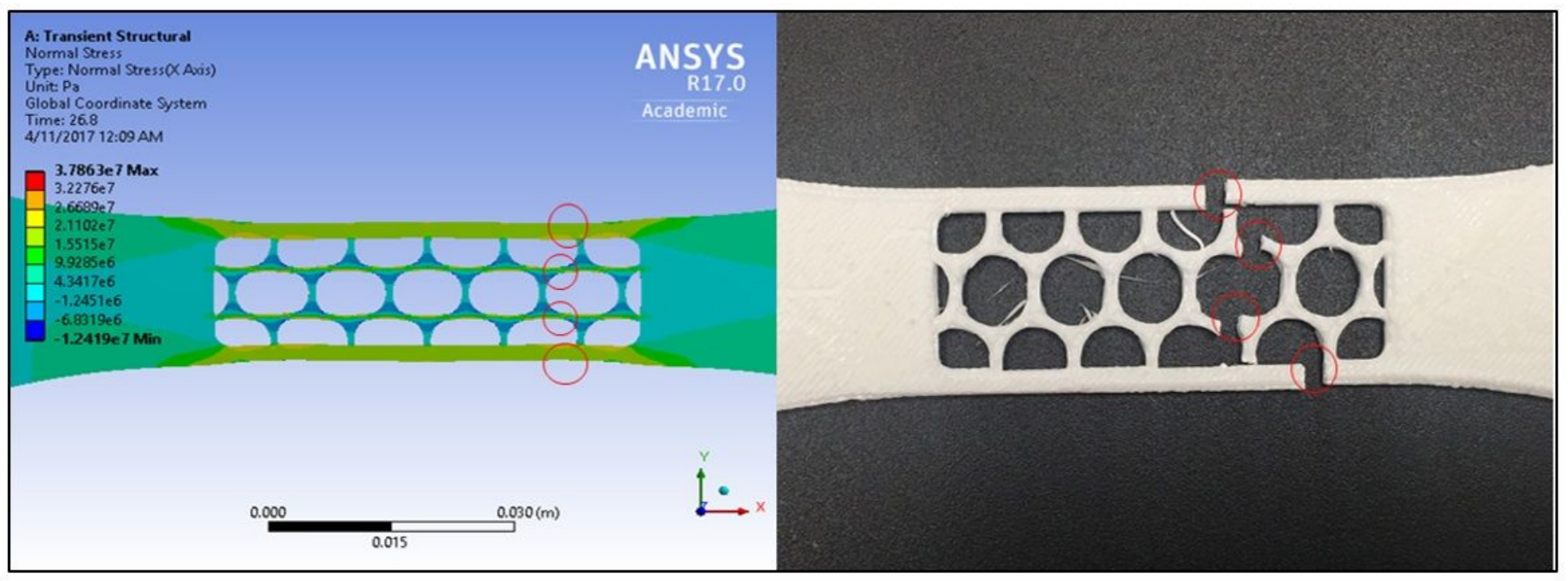

Figure 9

Stress plot for CP: left - FEA contour plot, right - actual fractured part. 


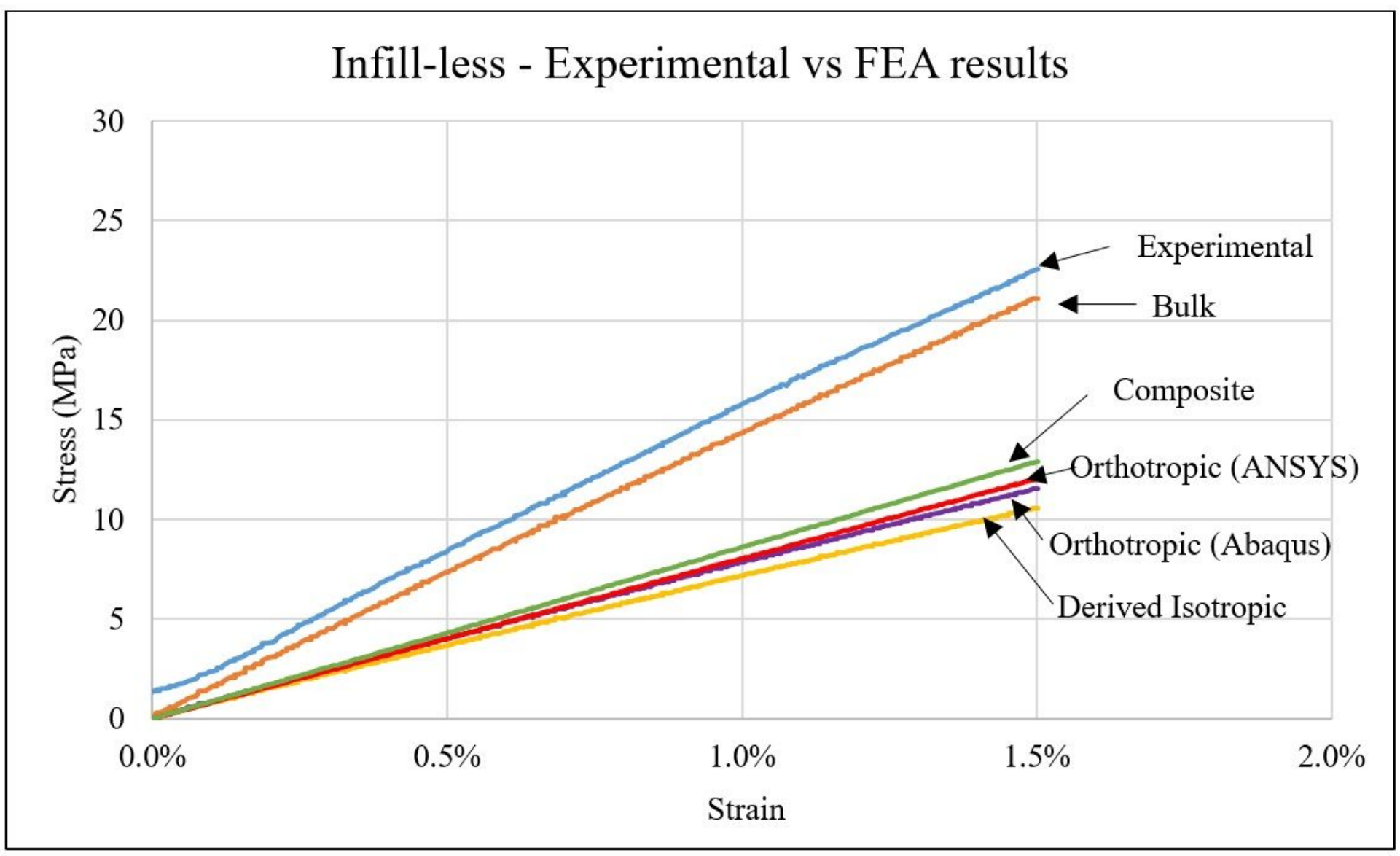

Figure 10

Stress-strain plot for I: Experimental and Simulated results.

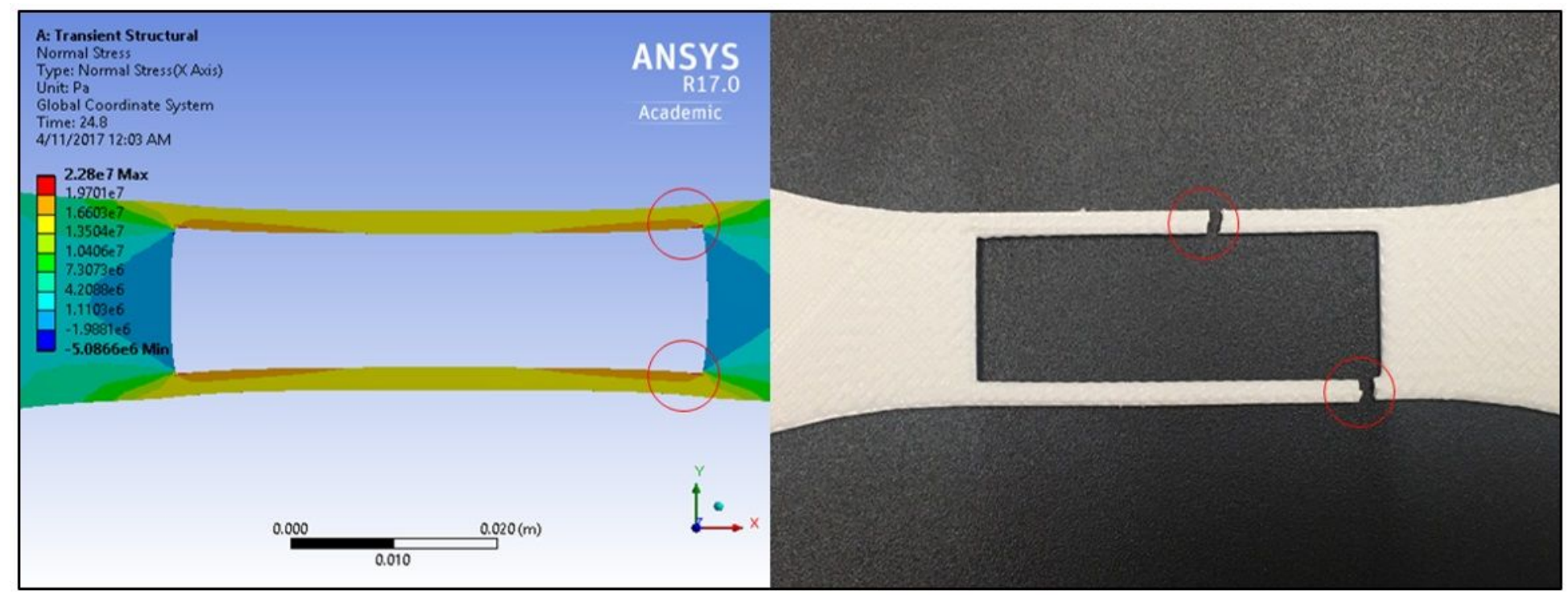

Figure 11

Stress plot for I: left - FEA contour plot, right - actual fractured part. 


\section{Error - Experimental vs Analytical}

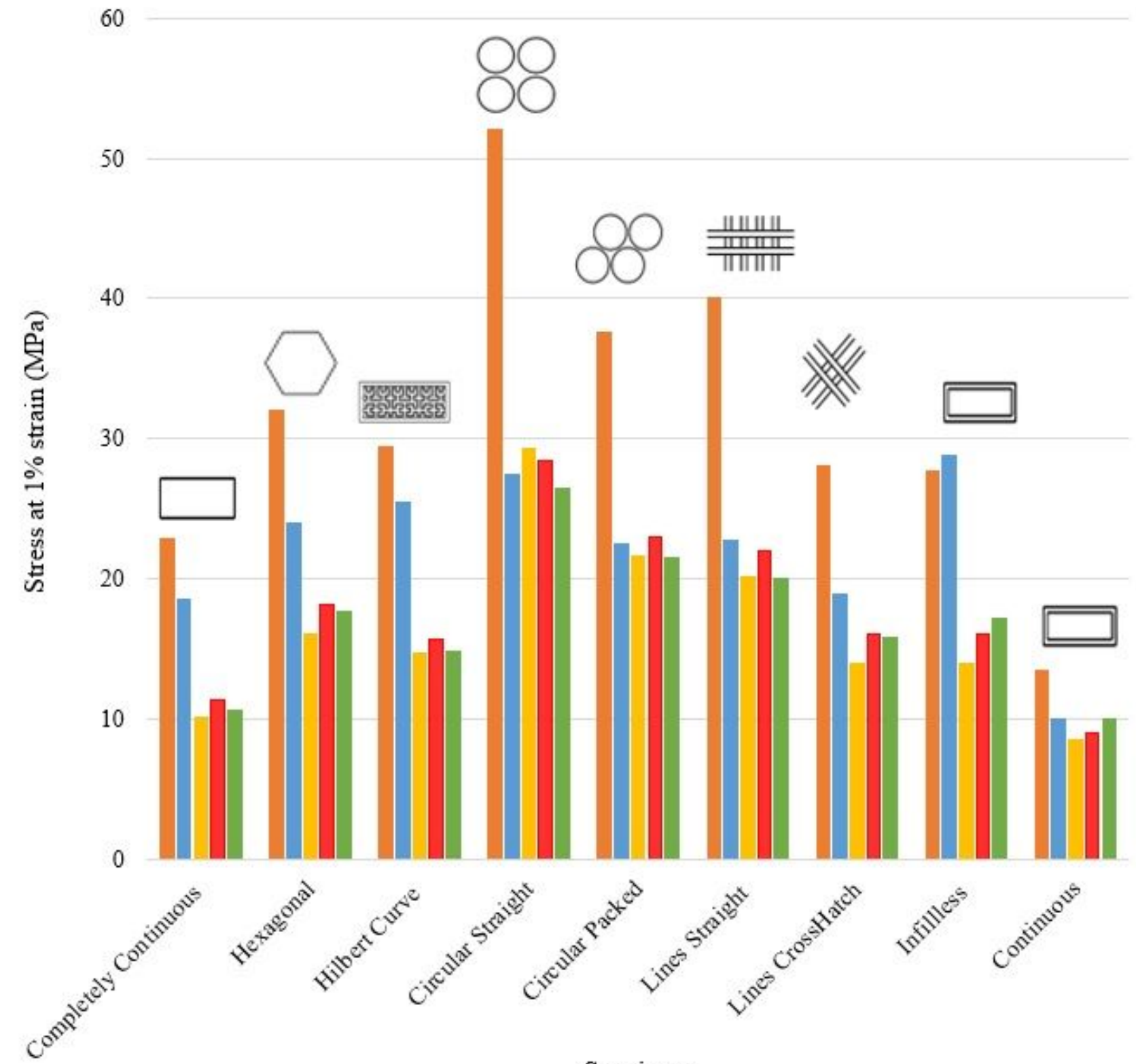

Specimen

Bulk Isotropic Mode1 $\quad$ Experimental Derived Isotropic Model घOrthotropic Derived Model $\mathbf{m}$ Composite Lamina Model

Figure 12

Summary of errors between FEA simulations and experimental results. 